\title{
Maternal $H$. pylori seropositivity is associated with gestational hypertension but is irrelevant to fetal growth and development in early childhood
}

Fu-Ping Lai ${ }^{1}$, Yi-Fang Tu ${ }^{1,3}$, Bor-Shyang Sheu ${ }^{2,3}$ and Yao-Jong Yang ${ }^{1,3^{*}}$ (D)

\begin{abstract}
Background: Helicobacter pylori infection is known to alter growth-related hormones and affect growth in young children. However, it is still unknown whether maternal H. pylori infection has an impact on the levels of cord blood growth-related hormones and whether this can predict intrauterine growth restriction and poor physical and neurodevelopmental outcomes in children. This study aimed to examine associations between maternal $\mathrm{H}$. pylori infection and pregnancy-related adverse events, fetal growth and early childhood development.

Methods: In this prospective cohort study, we recruited singleton pregnant women without major medical illnesses from January 2014 to January 2015. Seropositivity for H. pylori was defined as $>12 \mathrm{U} / \mathrm{ml}$ of anti-H. pylori lgG in maternal serum. Demographic data and pregnancy-related medical issues of the cohort were documented. Cord blood levels of insulin-like growth factor-1 (IGF-1), insulin-like growth factor binding protein-3 (IGFBP-3), insulin, and ghrelin were determined using ELISA. The growth of the included neonates was monitored annually for up to 3 years, and cognitive development was assessed using the comprehensive developmental inventory for infants and toddlers (CDIIT) test 3 years after birth.
\end{abstract}

Results: Of the 106 enrolled women, 25 (23.6\%) were H. pylori-seropositive. Maternal H. pylori seropositivity was correlated with a higher risk of developing gestational hypertension $(\mathrm{GH})(12 \%$ vs. 1.2\%, $p=0.04)$ and lower cord blood levels of IGF-1 ( $<35 \mathrm{ng} / \mathrm{ml}, 70.0 \%$ vs. $40.7 \%, p=0.02)$ and IGFBP-3 $(<1120 \mathrm{ng} / \mathrm{ml}, 100.0 \%$ vs. $76.3 \%, p=0.02)$ compared with the seronegative women. No significant impacts on birth weight, childhood growth and cognitive development were found to be correlated with maternal H. pylori seropositivity during pregnancy.

Conclusions: Maternal H. pylori infection during pregnancy was more likely to lead to the development of GH, but was not correlated with fetal and childhood growth and development. In addition to close monitoring of hypertension, $H$. pylori eradication can be considered for mothers with H. pylori infection.

Keywords: Growth and development, Ghrelin, H. pylori, Insulin-like growth factor-1, Gestational hypertension, Child, Pregnancy

\footnotetext{
* Correspondence: yaojong@mail.ncku.edu.tw

${ }^{1}$ Departments of Pediatrics, National Cheng Kung University Hospital, Medical

College, National Cheng Kung University, 138 Sheng Li Rd, Tainan 70428,

Taiwan

${ }^{3}$ Institutes of Clinical Medicine, National Cheng Kung University Hospital,

Medical College, National Cheng Kung University, Tainan, Taiwan

Full list of author information is available at the end of the article
}

(c) The Author(s). 2019 Open Access This article is distributed under the terms of the Creative Commons Attribution 4.0 International License (http://creativecommons.org/licenses/by/4.0/), which permits unrestricted use, distribution, and

reproduction in any medium, provided you give appropriate credit to the original author(s) and the source, provide a link to the Creative Commons license, and indicate if changes were made. The Creative Commons Public Domain Dedication waiver (http://creativecommons.org/publicdomain/zero/1.0/) applies to the data made available in this article, unless otherwise stated. 


\section{Background}

Helicobacter pylori infects more than half of the global population, although its prevalence varies widely among different countries. Low socioeconomic status and poor sanitary or hygienic conditions are associated with the prevalence of $H$. pylori infection. Primary $H$. pylori infections occur most commonly in early childhood, with reported annual spontaneous seroreversion rates ranging from 1 to $2 \%$ both in children and adults [1, 2]. Although it seldom causes clinical symptoms in children, chronic $H$. pylori infection can pose serious health threats, and the bacterium has been reported to promote the development of chronic gastritis, peptic ulcer diseases, MALT lymphoma and gastric cancer in $10 \%$ of the infected population. Furthermore, there is growing evidence, mainly obtained from observational studies, showing that $H$. pylori infection may impair growth in children [3-5]. H. pylori-induced chronic gastritis results in the loss of appetite, malabsorption of nutrients, and dysregulation of the gastric endocrine and growth hormone systems, all of which may contribute to childhood growth impairment [6]. We previously showed that the successful eradication of $H$. pylori can restore systemic ghrelin levels and improve growth in children [7].

$H$. pylori infection during pregnancy has been associated with several adverse outcomes in both mothers and neonates $[8,9]$. Two cohort studies conducted in Uganda and Sudan demonstrated that maternal $H$. pylori infection was correlated with a low neonatal birth weight $[10,11]$, however this effect was not observed in mouse models [12]. Another prospective cohort study conducted in the Netherlands identified $H$. pylori infection as an independent risk factor for frequent vomiting during pregnancy, and that this was correlated with an increase in the incidence of small for gestational age (SGA) neonates [8]. Moreover, a separate case-control study revealed that a significantly higher percentage of women positive for $H$. pylori stool antigen (HPSA) (indicative of $H$. pylori infection) developed preeclampsia (PE) with intrauterine growth restriction (IUGR) compared with HPSA-negative women. It is thought that $H$. pylori-induced iron deficiency anemia (IDA) also plays a role in driving IUGR [13, 14]. These results indicate possible etiopathological connections between maternal $H$. pylori infection and IUGR. It has previously been documented that cord blood levels of insulin, insulin-like growth factors (IGFs), insulin-like growth factor binding proteins (IGFBPs), and ghrelin are correlated with intrauterine fetal growth [15-18]. However, no previous study has addressed the role of these growth factors and hormones in maternal $H$. pylori infection and IUGR.

Children born SGA are associated with poor neurodevelopmental outcomes [19-21]. Similarly, H. pylori infection has been negatively correlated with cognitive development in children of early school age [22]. Interestingly, intraperitoneal injections of $H$. pylori filtrate have been shown to be sufficient to induce spatial learning and memory deficits in rats [23]. However, it is currently unclear whether maternal $H$. pylori infection has a negative impact on the neurodevelopment potential of the fetus. In this prospective cohort study, we investigated the effects of maternal $H$. pylori infection and related pregnancy disorders on the growth and development of fetuses, neonates, and during early childhood.

\section{Methods}

\section{Subject recruitment and follow-up}

Singleton pregnant women who attended regular antenatal examinations at one obstetric-pediatric clinic in Tainan City, Taiwan, between January 2014 and January 2015 were identified and recruited into this study. Eligibility was then assessed between 28 and 32 weeks of gestation. Individuals with underlying medical conditions such as chronic hypertension, pre-gestational diabetes mellitus, chronic lung disease, renal disease, major cardiac disease, autoimmune conditions, thyroid disease, malignancy, and uterine malformations were excluded. Individuals that had a history of illicit drug abuse and those whose fetuses had chromosomal abnormalities, congenital malformations or evident congenital infections (TORCH) were also excluded. Follow-up assessments were carried out at the time of delivery, and at 1 , 2 , and 3 years after delivery.

This study was approved by the Ethics Committee (BBR102-001) of National Cheng Kung University Hospital, Tainan, Taiwan, and written informed consent was obtained from each participant and her spouse. The demographic characteristics, anthropometric data, and common risk factors of SGA were collected and assessed, including maternal age, body height, body weight before pregnancy, body mass index (BMI) before pregnancy, smoking tobacco, alcohol use, maternal educational attainment, annual household income, and pregnancy complications such as antepartum bleeding, anemia, pregnancy-induced hypertension (PIH), and PE. Anemia was defined as a hemoglobin concentration of $<$ $11 \mathrm{~g} / \mathrm{dL}$. PIH was defined as any new onset of hypertension (systolic blood pressure $\geq 140 \mathrm{mmHg}$ and/or diastolic blood pressure $\geq 90 \mathrm{mmHg}$ ) after 20 weeks of gestation. PE was defined as a combination of PIH and proteinuria or signs of end-organ dysfunction.

The corresponding neonates enrolled in the follow-up were full-term (gestational age 37-40 weeks) and healthy. Parameters recorded at birth included gestational age, body weight and length, head circumference, and Apgar score at 1 and 5 min post-delivery. Neonates that required post-delivery intensive care were excluded from the follow-up study. 


\section{Maternal serum collection and testing for anti-H. pylori IgG}

The status of $H$. pylori infection was assessed by measuring serum IgG against $H$. pylori using a commercial $H$. pylori IgG ELISA kit (IBL, Hamburg, Germany) at 2832 weeks of gestation, the period when a routine screening test for hepatitis B surface antigen is commonly conducted in Taiwan. Anti-H. pylori IgG titers > $12 \mathrm{U} /$ $\mathrm{ml}$ were considered to be positive, while titers $<8 \mathrm{U} / \mathrm{ml}$ were considered to be negative. Titer values between 8 and $12 \mathrm{U} / \mathrm{ml}$ were considered to be equivocal. The mothers were subsequently categorized as being either $H$. pylori-seropositive or $H$. pylori-seronegative according to the ELISA results.

Cord blood levels of IGF-1, IGFBP-3, insulin, and ghrelin Cord venous blood samples were collected at delivery and centrifuged at $3500 \mathrm{x}$ g for $30 \mathrm{~min}$ at $4{ }^{\circ} \mathrm{C}$ to separate the serum. The serum samples were stored at $80^{\circ} \mathrm{C}$. IGF-I (R\&D Systems, Inc. Minneapolis, MN, USA), IGFBP-3 (R\&D Systems, Inc. Minneapolis, MN, USA), insulin ((R\&D Systems, Inc. Minneapolis, MN, USA) and ghrelin (EMD Millipore Corporation, St. Charles, MO, USA) levels were measured using ELISA following the manufacturers' instructions.

\section{Assessment of anthropometric parameters and cognitive development of newborns}

The enrolled newborns were studied longitudinally for up to 3 years. The weight and length of each child were measured at birth and then annually. According to the gestational age of infants born in Taiwan, SGA was defined by a birth weight below the 10th percentile [24].

Cognitive development was assessed using the comprehensive developmental inventory for infants and toddlers (CDIIT) test at 3 years of age. The CDIIT is a reliable pediatric norm-referenced assessment tool that is widely used for the clinical diagnosis of developmental delays in five major developmental areas, including cognition, language, motor, social and self-care skills [25, 26]. The CDIIT test consists of a diagnostic test (CDIITDT) and a screening test (CDIIT-ST). In this study, we applied the cognition subtest of the CDIIT-DT and assessed five aspects of a child's mental capacity, including attention, perception, memory, reasoning and concepts of color, shape, size, and number. The evaluations were conducted by a trained administrator.

\section{H. pylori stool antigen test (HPSA) and definition of $H$. pylori infection in children}

Stool samples were collected from the enrolled infants at 1, 2 and 3 years after birth to detect new $H$. pylori infections using the HPSA test. The HPSA test (Meridian Diagnostic Inc., Cincinnati, Ohio, USA) uses a plurality of monoclonal anti- $H$. pylori antibodies adsorbed to microwells. The results were interpreted spectrophotometrically, and the cutoff optical density at $450 \mathrm{~nm}$ for a positive outcome was set at 0.14 . Children with a positive HPSA test in any one of the three samples were considered to be infected with $H$. pylori, while those who had a negative HPSA test result following a previous positive result were defined as having spontaneous elimination of $H$. pylori infection. A minimum of two consecutive positive HPSA tests during the follow-up period was considered to indicate persistent $H$. pylori infection. Children with negative HPSA tests throughout the follow-up period were considered to be noninfected.

\section{Statistical analysis}

Demographic data and measurable parameters were presented as frequencies and means \pm standard deviations (SDs). Significance of association was determined using the Pearson chi-square $\left(\mathrm{x}^{2}\right)$ test for categorical variables and the independent sample $t$-test for continuous variables. As ELISA tests tend to produce high SD values which may give rise to type II statistical errors, receiver operating characteristic (ROC) curve analysis in conjunction with Youden's index was used to determine the best cutoff values of cord blood IGF-1, IGFBP-3, insulin and ghrelin levels to differentiate $H$. pylori-seropositive and $H$. pylori-seronegative mothers. A $p$ value of less than 0.05 was considered to be statistically significant. All statistical analyses were performed using SPSS Statistics V.17.0.

\section{Results}

Study design and enrolled subjects

Figure 1 shows the workflow of the study and the data collected. A total of 108 singleton pregnant women were initially recruited. Two participants were eventually excluded due to chronic hypertension and thyroid disease. The sera of the remaining 106 participants were collected and tested for anti-H. pylori IgG as specified. A total of 79 cord blood samples were analyzed for IGF-1, IGFBP-3, insulin, and ghrelin levels. For the follow-up assessments, five preterm newborns (gestational age $<37$ weeks) and one who was lost to follow-up were removed from the cohort.

\section{Seropositivity and clinical characteristics of the mothers}

Twenty-five (23.6\%) of the 106 pregnant women were positive for serum anti-H. pylori IgG (Table 1). There were no significant differences in age, pre-pregnancy body weight, height, BMI, household size, annual household income, educational attainment, job, smoking habit, alcohol drinking habit, hemoglobin, and placental weight between the two groups $(p>0.05)$. A significantly higher 


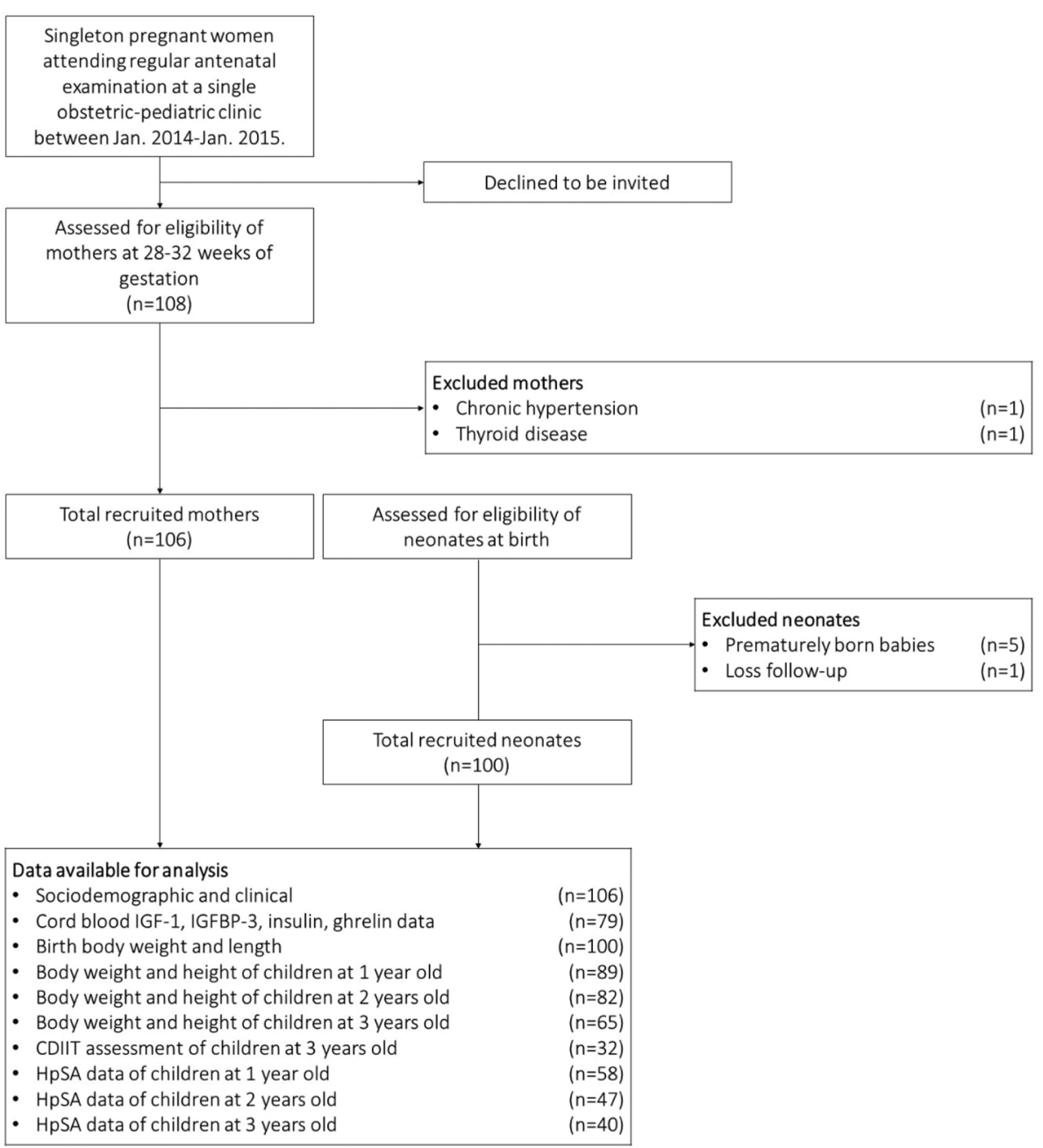

Fig. 1 The workflow and number of cases of the study

incidence rate of PIH was observed in the $H$. pylori-seropositive mothers than in the seronegative mothers $(12 \%$ vs $1.2 \%, p<0.05)$. In addition, the cord blood IGF- 1 and IGFBP-3 levels were modestly lower in the $H$. pyloriseropositive group compared with the seronegative group. According to our ROC curve analysis and Youden's index, the $H$. pylori-seropositive mothers were significantly more likely to have a cord blood IGF-1 level $<35 \mathrm{ng} / \mathrm{ml}(70.0 \%$ vs $40.7 \%, p=0.023)$ and IGFBP3 level $<1250 \mathrm{ng} / \mathrm{ml}(100 \%$ vs $76.3 \%, p=0.02)$ compared with the seronegative mothers (Table 2).

\section{Associations between maternal $\boldsymbol{H}$. pylori seropositivity and birth weight, early childhood growth, and cognitive development}

Table 3 shows the anthropometric data and cognitive development of the children with $H$. pylori-seropositive and seronegative mothers in the first 3 years after birth. No significant differences in body weight, length and head circumference at birth were observed between the $H$. pylori-seropositive group and seronegative group. Likewise, the rates of SGA and low birth weight (birth body weight $<2500 \mathrm{~g}$ ) were similar in the two groups. There were also no significant differences in body weight and height subsequently measured at 1,2 , and 3 years after birth between the children born to $H$. pylori-seropositive and seronegative mothers. Lastly, CDIIT assessments of the children at 3 years of age revealed no significant difference in cognitive development between the two groups of children (Table 3).

\section{Susceptibility to $H$. pylori infection in the children during the follow-up period}

Serial HPSA tests were performed in the children at 1,2 , and 3 years after birth. None of the 58 children who received HPSA tests were infected with $H$. pylori in the first year. In the second year, two of 16 children (12.5\%) from the $H$. pylori-seropositive group and one of 31 
Table 1 The characteristics of the mothers in the H. pylori-seropositive and seronegative groups

\begin{tabular}{|c|c|c|c|}
\hline \multirow[t]{2}{*}{ Variable, mean \pm SD or number (\%) } & \multicolumn{2}{|l|}{ Serum H. pylori lgG } & \multirow{2}{*}{$\begin{array}{l}p \\
\text { value }\end{array}$} \\
\hline & Seropositive $(n=25)$ & Seronegative $(n=81)$ & \\
\hline Maternal age (years) & $31.0 \pm 4.0$ & $32.1 \pm 3.8$ & 0.20 \\
\hline Maternal body height (cm) & $159.5 \pm 5.5$ & $159.9 \pm 4.4$ & 0.70 \\
\hline Maternal pre-pregnancy body weight (kg) & $52.2 \pm 5.9$ & $55.5 \pm 8.2$ & 0.06 \\
\hline Maternal pre-pregnancy BMI $\left(\mathrm{kg} / \mathrm{m}^{2}\right)$ & $20.6 \pm 2.5$ & $21.7 \pm 3.1$ & 0.09 \\
\hline Household size (person) & $3.8 \pm 1.7$ & $3.7 \pm 1.8$ & 0.69 \\
\hline Annual household income & & & 0.79 \\
\hline Low $^{a}$ & $7(28.0)$ & $25(30.9)$ & \\
\hline Middle/High & $18(72.0)$ & $56(69.1)$ & \\
\hline Educational attainment & & & 0.68 \\
\hline Low/Middle ${ }^{b}$ & $1(4.0)$ & $8(11.1)$ & \\
\hline High & $24(96.0)$ & $73(67.9)$ & \\
\hline Housewife & $5(20.0)$ & $25(30.9)$ & 0.45 \\
\hline Primigravida & $18(72.0)$ & $48(59.3)$ & 0.25 \\
\hline Smoking & $0(0.0)$ & $1(1.2)$ & 1.00 \\
\hline Alcohol & $3(12.0)$ & $5(6.2)$ & 0.39 \\
\hline Gestational age (weeks) & $38.5 \pm 1.0$ & $38.8 \pm 1.1$ & 0.26 \\
\hline Placental weight (g) & $505.2 \pm 65.3$ & $508.5 \pm 47.4$ & 0.79 \\
\hline Hemoglobin (g/dL) & $11.9 \pm 1.7$ & $11.9 \pm 1.4$ & 0.98 \\
\hline Pregnancy-induced hypertension & $3(12.0)$ & $1(1.2)$ & 0.04 \\
\hline Preeclampsia & $0(0.0)$ & $0(0.0)$ & 1.00 \\
\hline Bleeding at early gestation & $0(0.0)$ & $2(2.5)$ & 1.00 \\
\hline
\end{tabular}

${ }^{a}$ Annual household income $<16,200$ USD

${ }^{\mathrm{b}}$ Educational attainment below bachelor level

children (3.2\%) from the $H$. pylori-seronegative group were found to be HPSA positive $(p=0.26)$. In the third year, one more child from the maternal $H$. pylori-seropositive group was found to be HSPA positive. However, one child that was previously HSPA positive became HPSA negative, while two children remained HSPA positive (persistent infection).

\section{Analysis of the risk factors for SGA in singleton term neonates}

The risk factors for SGA were further evaluated (Table 4). There were no significant differences in maternal anthropometric and socio-demographic characteristics between the SGA and non-SGA groups. However, the SGA group exhibited a significantly lower placental weight (445.0 vs $514.9 \mathrm{~g}, p<0.01$ ), lower cord blood IGF-1 level (24.7 vs $40.1 \mathrm{ng} / \mathrm{mL}, p=0.04)$ and higher ghrelin level $(1045.1 \mathrm{vs} 782.3 \mathrm{pg} / \mathrm{mL}, p<0.01)$ compared with the non-SGA group.

\section{Discussion}

This is the first 3-year prospective cohort study to evaluate the relevant implications of maternal $H$. pylori infection during pregnancy on fetal growth, as well as growth and cognitive development in young children. Our results showed that the $H$. pylori-seropositive mothers had a higher risk of developing PIH during pregnancy. In addition, the $H$. pylori-seropositive mothers had lower levels of cord blood IGF-1 and IGFBP-3 than the seronegative mothers, even though no apparent changes in

Table 2 Associations between cord blood IGF-1, IGFBP-3, ghrelin, and insulin levels and maternal H. pylori seropositivity

\begin{tabular}{llll}
\hline Variable & Serum H. pylori lgG & & $p$ \\
\cline { 2 - 3 } Number (\%) & Seropositive $(n=20)$ & Seronegative $(n=59)$ & $24(40.7)$ \\
\hline IGF-1 $<35(\mathrm{ng} / \mathrm{ml})$ & $14(70.0)$ & $45(76.3)$ & 0.02 \\
IGFBP-3 $<1120(\mathrm{ng} / \mathrm{ml})$ & $20(100)$ & $38(64.4)$ & 0.02 \\
Insulin $<35(\mathrm{pmol} / \mathrm{l})$ & $17(85.0)$ & $16(27.1)$ & 0.10 \\
Ghrelin $>925(\mathrm{pg} / \mathrm{ml})$ & $3(15.0)$ & 0.37 \\
\hline
\end{tabular}


Table 3 The anthropometric characteristics and cognitive development of the children by maternal $H$. pylori status

\begin{tabular}{|c|c|c|c|}
\hline \multirow{2}{*}{$\begin{array}{l}\text { Variable } \\
\text { Mean } \pm \text { SD or number (\%) }\end{array}$} & \multicolumn{2}{|l|}{ Serum H. pylori lgG } & \multirow{2}{*}{$\begin{array}{l}p \\
\text { value }\end{array}$} \\
\hline & Seropositive $(n=23)$ & Seronegative $(n=77)$ & \\
\hline Birth body length $(\mathrm{cm})$ & $50.0 \pm 1.5$ & $50.1 \pm 2.1$ & 0.70 \\
\hline Birth head circumference $(\mathrm{cm})$ & $33.8 \pm 1.3$ & $33.9 \pm 1.4$ & 0.68 \\
\hline Birth body weight (g) & $3012.7 \pm 375.3$ & $3118.7 \pm 391.4$ & 0.25 \\
\hline Low birth weight < $2500 \mathrm{~g}$ & $2(8.7)$ & $4(5.2)$ & 0.62 \\
\hline Small for gestational age (SGA) & $2(8.7)$ & $8(10.4)$ & 1.00 \\
\hline \multicolumn{4}{|l|}{ Body weight (kg) } \\
\hline 1 year of age & $9.0 \pm 1.0(n=23)$ & $9.2 \pm 1.1(n=66)$ & 0.47 \\
\hline 2 years of age & $11.8 \pm 1.3(n=22)$ & $12.2 \pm 1.4(n=60)$ & 0.29 \\
\hline 3 years of age & $13.8 \pm 1.6(n=20)$ & $14.5 \pm 2.1(n=45)$ & 0.18 \\
\hline \multicolumn{4}{|l|}{ Body height $(\mathrm{cm})$} \\
\hline 1 year of age & $75.4 \pm 2.4(n=23)$ & $74.7 \pm 2.6(n=66)$ & 0.24 \\
\hline 2 years of age & $86.4 \pm 2.8(n=22)$ & $87.1 \pm 3.6(n=60)$ & 0.45 \\
\hline 3 years of age & $94.0 \pm 3.7(n=20)$ & $95.6 \pm 4.7(n=45)$ & 0.19 \\
\hline Domains of the CDIIT test & $(n=14)$ & $(n=18)$ & \\
\hline Attention & $109.3 \pm 16.9$ & $108.2 \pm 18.9$ & 0.87 \\
\hline Perception & $106.9 \pm 13.6$ & $106.4 \pm 15.2$ & 0.93 \\
\hline Memory & $106.4 \pm 22.9$ & $107.6 \pm 23.9$ & 0.89 \\
\hline Reasoning & $110.1 \pm 15.3$ & $110.8 \pm 17.1$ & 0.91 \\
\hline Concepts & $105.3 \pm 16.2$ & $103.5 \pm 20.9$ & 0.79 \\
\hline
\end{tabular}

birth weight and neonatal size were observed. Our results suggested that early childhood growth and cognitive development were not affected by maternal $H$. pylori infection during pregnancy.

In contrast to our observations, a previous study conducted by Eslick et al. reported that H. pylori-seropositive mothers were more likely to give birth to undersized neonates than seronegative women due to IUGR [27]. In a separate study conducted in Uganda, Wanyama et al. showed that maternal $H$. pylori infection was an independent predictor of low birth weight in newborns [10]. Likewise, Mustafa et al. also demonstrated that maternal H. pylori seropositivity was more frequently associated with low birth weight [11]. However, these studies did not consider the effects of other potential confounding events that are commonly experienced during pregnancy, such as severe nausea, vomiting, PE, and anemia.
We hypothesize that these factors could potentially explain the discrepant findings between previous studies and the current study.

Although not entirely understood, the mechanism by which maternal $H$. pylori infection impacts birth weight may be multifactorial. Maternal $H$. pylori infection has been reported to be a risk factor for hyperemesis gravidarum, PE, and IDA during pregnancy [8, 13, 28-30], and these events also contribute to SGA or IUGR. Interestingly, virulent factors of $H$. pylori have also been considered to be a cause of IUGR. Similarly, previous studies have reported that persistent CagA/VacA-positive $H$. pylori infection in pregnant women can cause PE and IUGR [31], and that SGA was correlated specifically with infections caused by CagA-positive strains of $H$. pylori [32]. Although the virulence factors of $H$. pylori from infected mothers were not tested in the current

Table 4 The risk factors for SGA using univariate analysis

\begin{tabular}{llll}
\hline Variable, Mean \pm SD & SGA & Non-SGA & $p$ value \\
\hline Placental weight $(\mathrm{g})$ & $445.0 \pm 47.9(n=10)$ & $514.9 \pm 47.4(n=90)$ & $<0.01$ \\
IGF-1 $(\mathrm{ng} / \mathrm{mL})$ & $24.7 \pm 10.5(\mathrm{n}=7)$ & $40.1 \pm 18.8(\mathrm{n}=69)$ & 0.04 \\
IGFBP-3 $(\mathrm{ng} / \mathrm{mL})$ & $834.5 \pm 363.7(\mathrm{n}=7)$ & $759.1 \pm 323.8 \mathrm{n}(\mathrm{n}=69)$ & 0.56 \\
Insulin $(\mathrm{pmol} / \mathrm{L})$ & $22.7 \pm 17.9(\mathrm{n}=7)$ & $29.9 \pm 29.3(\mathrm{n}=69)$ & 0.53 \\
Ghrelin $(\mathrm{pg} / \mathrm{mL})$ & $1045.1 \pm 241.6(\mathrm{n}=7)$ & $774.3 \pm 195.8(\mathrm{n}=69)$ & $<0.01$ \\
\hline
\end{tabular}


study, almost all strains of $H$. pylori isolated from Taiwanese patients are CagA/VacA-positive [33]. Notably, the rate of PIH was higher in the $H$. pylori-seropositive group compared with the seronegative group. However, no significant correlations were observed for anemia or preeclampsia.

Since $H$. pylori infection has been reported to alter growth hormones [32], we investigated the effects of $H$. pylori infection on cord blood levels of IGF-1, IGFBP-3, insulin, and ghrelin, as well as the relationships between these hormones and IUGR. Consistent with previous studies which reported decreased levels of IGF-1, IGFBP-3, and insulin, and increased levels of ghrelin in the cord blood of IUGR neonates [17, 34-36], our data showed significantly lower levels of IGF-1 and higher levels of ghrelin in the cord blood samples from the SGA neonates compared with those from the non-SGA neonates. Our results also revealed that maternal $H$. pylori-seropositivity during pregnancy was correlated with lower levels of IGF-1 and IGFBP-3 in the cord blood. However, of all the potential risk factors and parameters considered, only placental weight, but not PIH or $\mathrm{H}$. pylori-seropositivity, was found to be associated with SGA.

Taken together, it is likely that $H$. pylori infection during pregnancy causes SGA via indirect mechanisms such as the aforementioned adverse effects that are commonly associated with $H$. pylori infection. However, further studies are required to confirm this.

The data obtained in the current study indicated that there were no significant differences in early childhood growth and cognitive development between the children born to $H$. pylori-seropositive mothers and seronegative mothers. In addition, maternal $H$. pylori-seropositivity during pregnancy did not increase the risk of acquiring H. pylori infection in children. This is consistent with our observations that maternal $H$. pylori infection status did not affect initial birth weight.

There are several limitations to this study. First, SGA was used as a surrogate for IUGR. However, this clinical definition does not distinguish between constitutionally and pathologically small fetuses $[37,38]$. On the other hand, although suffering from intrauterine growth deceleration, IUGR infants may have appropriate birth weight as per gestation. "True" IUGR infants are mostly a consequence of placental insufficiency, and they present with poorer perinatal and long-term outcomes compared with constitutionally SGA neonates [38, 39]. Thus, ways to more effectively distinguish neonates with IUGR would be more clinically relevant. Second, not all risk factors of SGA were considered in this study. SGA risk factors such as maternal weight gain, nutritional status during pregnancy, PE and the prevalence and severity of hyperemesis gravidarum may also play important roles and should therefore be studied in the future. Indeed, maternal weight gain during pregnancy has been shown to be positively correlated with neonatal birth weight [40]. Third, given that placental weight was negatively correlated with the risk of SGA [41, 42], we relied on placental weight as a representative of overall placental condition. However, more in-depth evaluations of specific placental parameters such as uterine artery velocimetry or expression of biomarkers should be performed. This would allow important weight-independent physiological and pathological changes of the placenta to be detected more effectively. Furthermore, our serology $H$. pylori IgG test, which was used to define infection status in our cohort, did not distinguish previously cleared infections from ongoing infections [43]. Lastly, there were missing data during the 3-year follow-up period, which may have led to bias in the results.

\section{Conclusions}

In this prospective cohort study in Taiwan, we found that maternal $H$. pylori infection per se did not promote SGA in neonates. We showed that SGA was most likely caused by other $H$. pylori-induced pathologies and pregnancy-related complications such as hyperemesis gravidarum, PE, and anemia. Moreover, we revealed that maternal $H$. pylori infection did not directly impair growth and cognitive development during early childhood. However, as H. pylori-infected pregnant women are more likely to develop $\mathrm{PIH}$, increased attention should be paid to prevent hypertension-related complications in these individuals. Future studies to investigate the possible mechanisms by which $H$. pylori directly affects PIH and to assess whether $H$. pylori eradication can decrease the risk of PIH for mothers are warranted.

\section{Abbreviations}

BMI: body mass index; CDIIT: comprehensive developmental inventory for infants and toddlers; GH: gestational hypertension; HPSA: H. pylori stool antigen; IDA: iron deficiency anemia; IGFBPs: insulin-like growth factors binding proteins; IGFs: insulin-like growth factors; IUGR: intrauterine growth restriction; PE: preeclampsia; SGA: small for gestational age

\section{Acknowledgements}

The authors wish to thank Dr. Shu-Ching Huang and Dr. Chih-Ta Yao (Fu-ErAn Women \& Children Clinic, Tainan, Taiwan) for their study support. They assisted in data collection and following up the infants' health status.

\section{Authors' contributions \\ FPL was involved in the study design, study conduction, interpretation of data, and in drafting the manuscript. YFT contributed to the study design and to the interpretation of data. BSS was involved in the study design and conduction, interpretation of data, and editing the manuscript. YJY contributed to the setting of the study design and conduction, interpretation of data, editing and final approval of the manuscript. All authors have read and approved the manuscript.}

\section{Funding}

This study was supported by a grant NSC 102-2314-B-006-025- from the National Science Council, Taiwan. The funding entities had no role in study design, data collection, data analysis, data interpretation, manuscript preparation, or the decision to submit the manuscript for publication. 


\section{Availability of data and materials}

The datasets used and analyzed during the current study are available from the corresponding author on reasonable request.

\section{Ethics approval and consent to participate}

The study was approved by the Ethics Committee (B-BR102-001) of National Cheng Kung University Hospital, Tainan, Taiwan. Written informed consent was obtained from each participant and her spouse.

\section{Consent for publication}

Not applicable.

\section{Competing interests}

The authors declare that there were no competing interests.

\section{Author details}

${ }^{1}$ Departments of Pediatrics, National Cheng Kung University Hospital, Medical College, National Cheng Kung University, 138 Sheng Li Rd, Tainan 70428, Taiwan. ${ }^{2}$ Internal Medicine, National Cheng Kung University Hospital, Medical College, National Cheng Kung University, Tainan, Taiwan. ${ }^{3}$ Institutes of Clinical Medicine, National Cheng Kung University Hospital, Medical College, National Cheng Kung University, Tainan, Taiwan.

\section{Received: 4 October 2019 Accepted: 28 November 2019}

\section{Published online: 16 December 2019}

\section{References}

1. Kumagai T, Malaty HM, Graham DY, Hosogaya S, Misawa K, Furihata K, et al. Acquisition versus loss of Helicobacter pylori infection in Japan: results from an 8-year birth cohort study. J Infect Dis. 1998;178:717-21.

2. Malaty HM, El-Kasabany A, Graham DY, Miller CC, Reddy SG, Srinivasan SR, et al. Age at acquisition of Helicobacter pylori infection: a follow-up study from infancy to adulthood. Lancet. 2002;359:931-5.

3. Muhsen K, Goren S, Cohen D. Helicobacter pylori infection in early childhood and growth at school age. Helicobacter. 2015;20:410-7.

4. Kocaoglu C, Ozel A, Cayci M, Solak ES. Effect of long-term Helicobacter pylori infection on growth of children: a cohort study. World J Pediatr. 2016;12:196-201.

5. Dror G, Muhsen K. Helicobacter pylori infection and children's growth: an overview. J Pediatr Gastroenterol Nutr. 2016;62:e48-59.

6. Franceschi F, Annalisa T, Teresa DR, Giovanna D, laniro G, Franco S, et al. Role of Helicobacter pylori infection on nutrition and metabolism. World J Gastroenterol. 2014;20:12809-17.

7. Yang YJ, Sheu BS, Yang HB, Lu CC, Chuang CC. Eradication of Helicobacter pylori increases childhood growth and serum acylated ghrelin levels. World J Gastroenterol. 2012:18:2674-81.

8. Grooten IJ, Den Hollander WJ, Roseboom TJ, Kuipers EJ, Jaddoe WW, Gaillard R, et al. Helicobacter pylori infection: a predictor of vomiting severity in pregnancy and adverse birth outcome. Am J Obstet Gynecol. 2017;216:512.e1-9.

9. Cardaropoli S, Rolfo A, Todros T. Helicobacter pylori and pregnancy-related disorders. World J Gastroenterol. 2014;20:654-64.

10. Wanyama R, Kagawa MN, Opio KC, Baingana RK. Effect of maternal Helicobacter pylori infection on birth weight in an urban community in Uganda. BMC Pregnancy Childbirth. 2016;16:158.

11. Mustafa A, Bilal NE, Abass AE, Elhassan EM, Adam I. The association between Helicobacter pylori seropositivity and low birthweight in a Sudanese maternity hospital. Int J Gynaecol Obstet. 2018;143:191-4.

12. Gøbel R, Symonds EL, Butler RN, Tran CD. Association between Helicobacter pylori infection in mothers and birth weight. Dig Dis Sci. 2007:52:3049-53.

13. Nashaat EH, Mansour GM. Helicobacter pylori and anemia with pregnancy. Arch Gynecol Obstet. 2014;289:1197-202.

14. Elkhouly NI, Elkelani OA, Elhalaby AF, Shabana AA. Relation between Helicobacter pylori infection and severe PE complicated by intrauterine growth restriction in a rural area in Egypt. J Obstet Gynaecol. 2016;36:1046-9.

15. Verhaeghe J, Van Bree R, Van Herck E, Laureys J, Bouillon R, Van Assche FA. C-peptide, insulin-like growth factors I and II, and insulin-like growth factor binding protein-1 in umbilical cord serum: correlations with birth weight. Am J Obstet Gynecol. 1993;169:89-97.

16. Farquhar J, Heiman M, Wong AC, Wach R, Chessex P, Chanoine JP. Elevated umbilical cord ghrelin concentrations in small for gestational age neonates. J Clin Endocrinol Metab. 2003;88:4324-7.
17. Martos-Moreno GA, Barrios V, Sáenz de Pipaón M, Pozo J, Dorronsoro I, Martínez-Biarge M, et al. Influence of prematurity and growth restriction on the adipokine profile, IGF1, and ghrelin levels in cord blood: relationship with glucose metabolism. Eur J Endocrinol. 2009;161:381-9.

18. Abdel Hakeem AH, Saed SZ, El Rehany MA, Yassin EE. Serum level of ghrelin in umbilical cord in small and appropriate for gestational age newborn infants and its relationship to anthropometric measures. J Clin Neonatol. 2012;1:135-8

19. Levine TA, Grunau RE, McAuliffe FM, Pinnamaneni R, Foran A, Alderdice FA. Early childhood neurodevelopment after intrauterine growth restriction: a systematic review. Pediatrics. 2015;135:126-41.

20. Murray E, Fernandes M, Fazel M, Kennedy SH, Villar J, Stein A. Differential effect of intrauterine growth restriction on childhood neurodevelopment: a systematic review. BJOG. 2015;122:1062-72.

21. Takeuchi A, Yorifuji T, Takahashi K, Nakamura M, Kageyama M, Kubo T, et al. Neurodevelopment in full-term small for gestational age infants: a nationwide Japanese population-based study. Brain and Dev. 2016;38:529-37.

22. Muhsen K, Ornoy A, Akawi A, Alpert G, Cohen D. An association between Helicobacter pylori infection and cognitive function in children at early school age: a community-based study. BMC Pediatr. 2011;11:43.

23. Wang XL, Zeng J, Feng J, Tian YT, Liu YJ, Qiu M, et al. Helicobacter pylori filtrate impairs spatial learning and memory in rats and increases $\beta$-amyloid by enhancing expression of presenilin-2. Front Aging Neurosci. 2014;6:66.

24. Hsieh WS, Wu HC, Jeng SF, Liao HF, Su YN, Lin SJ, et al. Nationwide singleton birth weight percentiles by gestational age in Taiwan, 1998-2002. Acta Paediatr Taiwan. 2006:47:25-33.

25. Wang TM. The comprehensive developmental inventory for infants and toddlers - manual. Taipei: Special Education Division, Ministry of Education; 2003.

26. Liao HF, Pan YL. Test-retest and inter-rater reliability for the comprehensive developmental inventory for infants and toddlers diagnostic and screening tests. Early Hum Dev. 2005;81:927-37.

27. Eslick GD, Yan P, Xia HH, Murray H, Spurrett B, Talley NJ. Foetal intrauterine growth restrictions with Helicobacter pylori infection. Aliment Pharmacol Ther. 2002;16:1677-82.

28. Li L, Li L, Zhou X, Xiao S, Gu H, Zhang G. Helicobacter pylori infection is associated with an increased risk of hyperemesis gravidarum: a metaanalysis. Gastroenterol Res Pract. 2015;2015:278905.

29. Nourollahpour Shiadeh M, Riahi SM, Adam I, Saber V, Behboodi Moghadam Z, Armon B, et al. Helicobacter pylori infection and risk of preeclampsia: a systematic review and meta-analysis. J Matern Fetal Neonatal Med. 2019;32:324-31.

30. Mulayim B, Celik NY, Yanik FF. Helicobacter pylori infection detected by 14 Curea breath test is associated with iron deficiency anemia in pregnant women. J Obstet Gynaecol Res. 2008;34:980-5.

31. Cardaropoli S, Rolfo A, Piazzese A, Ponzetto A, Todros T. Helicobacter pylori's virulence and infection persistence define PE complicated by fetal growth retardation. World J Gastroenterol. 2011:17:5156-65.

32. Den Hollander WJ, Schalekamp-Timmermans S, Holster IL, Jaddoe WW Hofman A, Moll HA, et al. Helicobacter pylori colonization and pregnancies complicated by preeclampsia, spontaneous prematurity, and small for gestational age birth. Helicobacter. 2017;22 https://doi. org/10.1111/hel.12364.

33. Sheu SM, Sheu BS, Yang HB, Li C, Chu TC, Wu JJ. Presence of iceA1 but not cagA, cagC, cagE, cagF, cagN, cagT, or orf13 genes of Helicobacter pylori is associated with more severe gastric inflammation in Taiwanese. J Formos Med Assoc. 2002;101:18-23.

34. Chiesa C, Osborn JF, Haass C, Natale F, Spinelli M, Scapillati E, et al. Ghrelin, leptin, IGF-1, IGFBP-3, and insulin concentrations at birth: is there a relationship with fetal growth and neonatal anthropometry? Clin Chem. 2008:54:500-8.

35. Méndez-Ramírez F, Barbosa-Sabanero G, Romero-Gutiérrez G, Malacara JM. Ghrelin in small-for-gestational age (SGA) newborn babies: a cross-sectional study. Clin Endocrinol. 2009;70:41-6.

36. Lee $\mathrm{MH}$, Jeon $\mathrm{YJ}$, Lee SM, Park MH, Jung SC, Kim YJ. Placental gene expression is related to glucose metabolism and fetal cord blood levels of insulin and insulin-like growth factors in intrauterine growth restriction. Early Hum Dev. 2010;86:45-50.

37. Sharma D, Shastri S, Farahbakhsh N, Sharma P. Intrauterine growth restriction - part 1. J Matern Fetal Neonatal Med. 2016;29:3977-87.

38. Figueras F, Gratacos E. An integrated approach to fetal growth restriction. Best Pract Res Clin Obstet Gynaecol. 2017;38:48-58. 
39. Longo S, Bollani L, Decembrino L, Di Comite A, Angelini M, Stronati M Short-term and long-term sequelae in intrauterine growth retardation (IUGR). J Matern Fetal Neonatal Med. 2013;26:222-5.

40. Monte S, Valenti O, Giorgio E, Renda E, Hyseni E, Faraci M, et al. Maternal weight gain during pregnancy and neonatal birth weight: a review of the literature. J Prenat Med. 2011;5:27-30.

41. Sandovici I, Hoelle K, Angiolini E, Constância M. Placental adaptations to the maternal-fetal environment: implications for fetal growth and developmental programming. Reprod BioMed Online. 2012;25:68-89.

42. Eskild A, Romundstad PR, Vatten $\sqcup$. Placental weight and birthweight: does the association differ between pregnancies with and without preeclampsia? Am J Obstet Gynecol. 2009;201:595.e1-5.

43. Khalifehgholi M, Shamsipour F, Ajhdarkosh H, Ebrahimi Daryani N,

Pourmand MR, Hosseini M, et al. Comparison of five diagnostic methods for Helicobacter pylori. Iran J Microbiol. 2013;5:396-401.

\section{Publisher's Note}

Springer Nature remains neutral with regard to jurisdictional claims in published maps and institutional affiliations.

Ready to submit your research? Choose BMC and benefit from:

- fast, convenient online submission

- thorough peer review by experienced researchers in your field

- rapid publication on acceptance

- support for research data, including large and complex data types

- gold Open Access which fosters wider collaboration and increased citations

- maximum visibility for your research: over $100 \mathrm{M}$ website views per year

At BMC, research is always in progress.

Learn more biomedcentral.com/submissions 